\title{
Task-Based Dictation (TBD): A Means of Improving the Language Proficiency of College Students
}

\author{
Bethany Marie Cabantac-Lumabi ${ }^{1}$ \\ ${ }^{1}$ Far Eastern University, Manila, Philippines
}

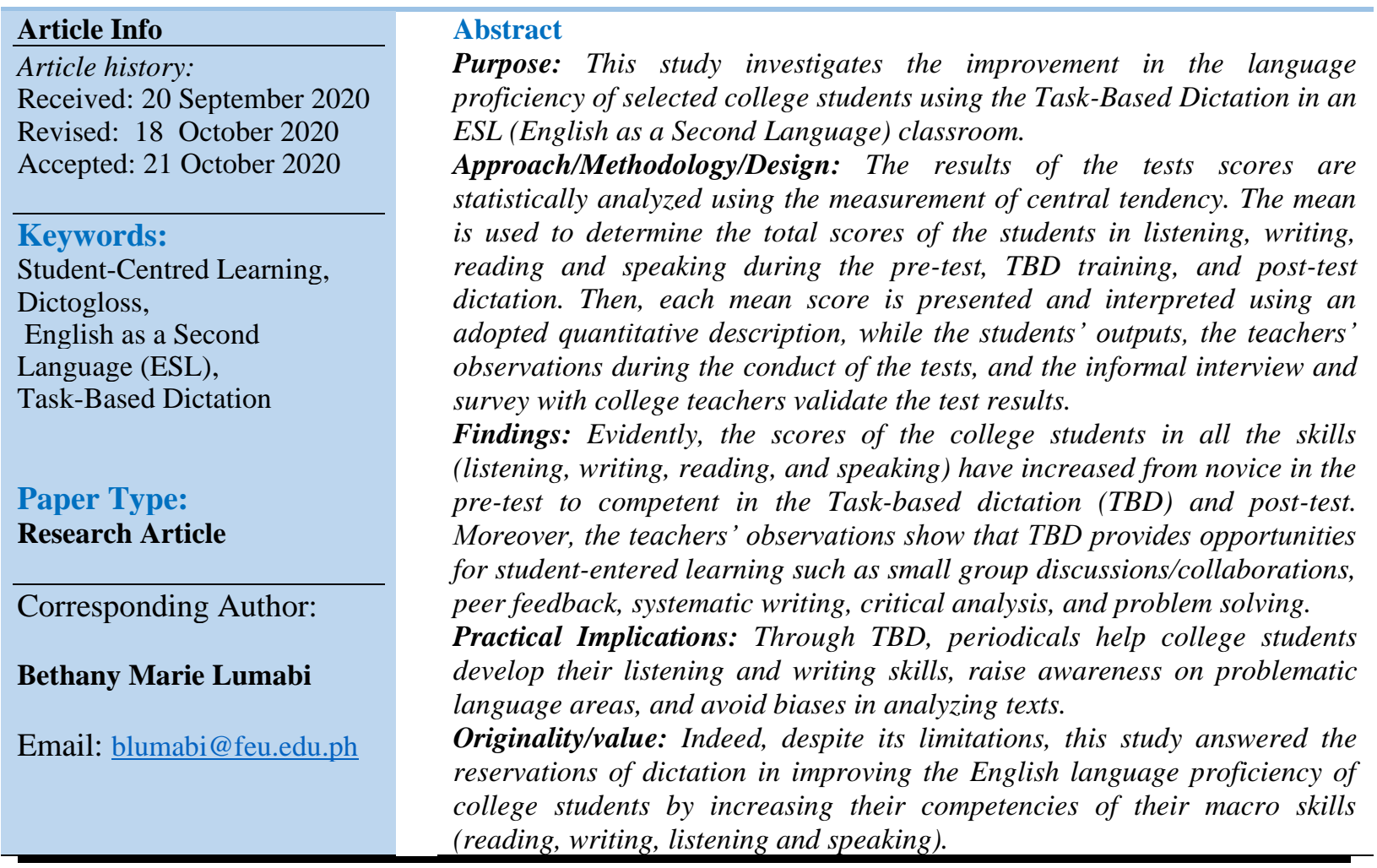

\section{Introduction}

In the history of Philippine education, English language proficiency has been a major challenge among students and teachers. Filipino learners have been exposed and have been taught about English since pre-school to college, yet until now school authorities are still exploring and studying programs to improve language proficiency and competence of the students. For language teachers, language proficiency and academic achievement are interrelated. Both comprise a range of different skills that students have to acquire. Filipino English teachers are still ambitious and positive on moulding their learners to become language proficient because "those competent in all language skills should be able to carry on their studies more successfully" (Rivera, 1984). The question of proficiency on "how much" and "what kind" deserves a careful consideration. 
English as a second language in the Philippines started during the American colonial administration (Rafael, 2015). Based on Philippine history - American Period, in 1901, Governor Taft declared English as a medium of instruction and six hundred American teachers were sent to the Philippines to teach the language (Casambre, 1982). The United States rule was accompanied by improvements in the education and health systems of the Philippines; school enrolment rates multiplied fivefold. In 1930s, literacy rates had reached fifty percent. Since then, English is taught in schools as one of the two official languages of the country, the other being Filipino, an official and liberalized form of Tagalog. English is used in education, religious affairs, print and broadcast media, and business. For highly technical subjects such as nursing, medicine, computing, etc. very few would prefer highly technical books in the vernacular. Movies and television programs in English are not subtitled and are expected to be directly understood (Espinosa, 1997).

Despite the long years of studying English, many Filipinos still lack proficiency in English language. In fact, the Filipinos' English Proficiency Index (EPI) ranked low, which placed the Philippines from the $14^{\text {th }}$ place in 2018 down to the $20^{\text {th }}$ place in 2019 among 100 countries in the world (Valderama, 2019). EPI measures the average level of English language skills based on the results of an online Standard English Test (EST) administered by the English Proficiency Education First, a Swiss-based global company focusing on language, academic, cultural exchange, and educational travel programs. It is even more depressing among college students, since the same source said that the level of English proficiency of college graduates from the Philippines was lower than the target English proficiency of high school students in Thailand based on the study by Hopkins International Partners. The Hopkins International Partners was the official representative of the Philippines to the Test of English for International Communication (TOEIC), an international standardized test of English language proficiency for non-native speakers that is designed to measure the everyday English skills of people working in an international environment (Valderama, 2019).

Clearly, this has been a perennial problem of language teachers which they have persistently tried to find solution through continuous research and study. Apparently, language teachers are determined to teach the four basic language skills: listening, speaking, reading and writing in the classroom. Definitely, a teaching methodology attractive to Filipino teachers and students within current approaches to language learning and teaching is a possible answer. Basically, an English teacher facilitates daily a 45-60 minute lesson which targets the macro skills (listening, speaking, reading and writing). In reality, this objective can be seldom done with the given limited time. Moreover, for a college teacher who facilitates an English class semi-weekly or three times a week with the same amount of time, it is more unrealistic to achieve the same goal. Traditionally, the teacher discusses solely the lesson to maximize the allotted time for the subject matter while the students listen.

Thus, Brown (2004) found listening significant in English lesson since "in a typical day, people do measurably more listening than speaking; whether in the workplace, educational, 
or home contexts, aural comprehension far outstrips oral production in quantifiable terms of time, number of words, effort and attention. His list of micro and macro skills in listening, adapted from Richards (1983), shows listening as a significant root to achieve the remaining skills (reading, speaking, writing). Whenever a teacher applies listening as his/her method regardless of its type (intensive, responsive, selective and extensive), language learners acquire most or all of the following skills. Teachers, therefore, need to pay close attention to listening as a mode of performance for assessment in the classroom (p. 119).

Then, to determine whether the students understood the lesson, the teacher expects written outputs from their end. On the other hand, supporting data about writing, Alinsunod (2014). concluded that language educators are satisfied with the written works of language learners which have good grammatical structures, appropriate punctuation marks, right tenses of verbs, right cases of pronouns, and correct spelling of words. Apparently, most English teachers follow those criteria until now. Furthermore, since listening is not observable, teachers assess its result among language learners through their writing performance and outputs. Brown (2004) emphasized that every educated child in developed countries learns the rudiments of writing his/her native language, but very few learn to express themselves clearly with logical, well-developed organization that accomplishes an intended purpose ( $\mathrm{p}$. 218). This led him to his list below of micro-skills and macro-skills of writing which demonstrates the necessary follow-up action for a successful listening.

Evidently, listening and writing remain the dominant skills, yet most neglected in an ESL class. Since listening and writing are often performed by students, reviving a teaching methodology using these skills may complete the missing pieces of the puzzle on English proficiency among ESL learners. However, this time, the methodology must not only use listening and writing but also it must achieve and practice reading and speaking to make the learners acquire language more effectively. One common and familiar methodology is safe for non-native teachers of English, dictation. Dictation has been used in language learning for centuries now and its value has been tested and proven by language authorities since then. According Stansfield (as cited in Norris, 1993), dictation is one of the oldest techniques known for both the teaching and testing of foreign languages way back in sixteenth century. It has long been associated with grammar-translation method. Eventually, through the years, dictation has fallen in and out of favour as new schools and approaches in language teaching emerge.

In Philippine classrooms, dictation is being used a testing technique not only in language courses, but also in other subject areas like Math, Science, History, etc. It has been popular among teachers of all levels. Davis and Rinvolucri (1988) attest that "dictation is a safe method for non-native teachers which ESL teachers can prepare fully in advance because the language it generates is known; it is not an exercise that will take teachers by surprise in the class by exposing them to unexpected language" (p. 7). Traditionally, dictation is a teachercentred strategy since a text is either read by the teacher while the students just listen and try to understand. The text is then broken into a number of short sections with a pause between 
each section. During that pause the students have to write down what they have heard. This is the only form of dictation many teachers and students have known, and is sometimes perceived as its downside.

This is the reason for opponents to strengthen its effectiveness because "dictation is primarily a test of spelling" (Somartne, as cited in Morris, 1983) and as a testing device; dictation must be regarded as generally both uneconomical and imprecise (Harris as cited in Morris, 1983). Furthermore, Lado (as cited in Morris, 1983) insisted that dictation extremely measures very little language. It does not even test the word order, vocabulary and aural perception. He added that the slow reading of a word is an incorrect production of sounds that the language learners must not follow. He concludes that dictation can only test writing skill instead.

Finocchiaro (1969) summarized confidently the value of dictation:

- It ensures attentive listening.

- It trains pupils to distinguish sounds.

- It helps fix concepts of punctuation.

- It enables pupils to learn to transfer oral sounds to written symbols.

- It helps develop aural comprehension.

- It assists self-evaluation.

Ridjanovic (in Bott, 1986) noted that large English classes (common in Philippine context) can be trained and tested in an important area of communicative competency by non-native teachers (like Filipino ESL teachers), who may themselves lack oral proficiency. Through this, dictation method has been developed for teachers of English who are able to start, play, stop a tape recorder, ask questions about content of an L2 (second language) passage and drill L2 structures and pronunciation of difficult words and phrases with the aid of tape (p. 42). As a whole, language proficiency comprises a range of different skills; proponents believe that dictation deals with these four macro skills in language learning. Davis and Rinvolucri (1988) emphasized that in normal use, language behaviour is generally accompanied by other activity involving the eye, the hand, the brain, etc. that sum up a number of factors reproducing the complexity in the language learning situation. Dictation (of any kind) provides a nice blend of listening, writing and checking through reading while speaking. This appeals to students whether they learn primarily in an auditory or visual or kinaesthetic way. In fact, Wong and Leeming (2014) found out that dictation was effective in separating the students into different levels based on proficiency. Since it is cheap and easy to conduct, it is a viable alternative when standardized proficiency scores for students are unavailable ( $\mathrm{p}$. $165)$.

Relatively, one of the easiest methods to prepare in a class is dictation because the teacher's voice is the only instrument to use and the text which the students/ teachers need to dictate. Likewise, Alkire (2002) shared a big list of benefits from dictation: (1) it conforms to diverse class population, then students can be tasked to do the correction on their own texts which 
could promote peer teaching as well; (2) it conforms diverse class level (college level vary in age and level of comprehension); (3) it applies "real world" skills since many jobs demand accurate understanding of spoken orders (phone agents, program developers, medical practitioners, administrative assistants, etc.).

In terms of dictation materials, this study maximized the potential of the periodicals as part of the pool of teaching materials for developing communicative competence. This might serve as an eye-opener for teachers and also students on the importance of the periodicals from which to draw not just information, but also varied skills needed for the use of English in the practical and realistic way such as dictation. Dictation using authentic materials can be a good indicator of language ability. It is an instructional method which when thoroughly exploited would develop students' highest language proficiency. In fact, the Al-Ansari's case study (as cited in Masangya and Lozada, 2009) affirms that competency in a new language is achieved through constant exposure of the intended language. Exposing the language learners to current events in English influences their own English habit.

Since the characteristics of TBD are similar to those of the Direct Method adapted by Krashen's Monitor Model (1983), the Monitor Hypothesis is a conscious learning that can function only as a monitor or editor that checks and repairs the output of the acquired system. The conscious grammar correction justifies that Acquisition Competence is responsible for the learners' fluent production of sentences. This acquired linguistic system initiate utterances, whereas the Learning Competence's function is just to correct sentences either before or after the learners' production. In this method, he hypothesized that the "natural order" allows the learners to follow a more or less invariant order in the acquisition of formal grammatical features. It affirms that when a learner is engaged in natural communication tasks, he will manifest the standard order. But, when is engaged in 'tasks" that require or permit the use of meta-linguistic knowledge, a different order will emerge. He added that this is the device that learners use to edit their language performance. It utilizes "learnt" knowledge by acting upon and modifying utterances generated from acquired knowledge.

Therefore, this study investigated the improvement in the language proficiency of selected college students using the Task Based Dictation in an ESL (English as a Second Language) classroom. Specifically, the following were the purpose of the study:

1. Measure the level of language proficiency of college students in each of the following using traditional dictation; listening, speaking, reading, writing

2. Measure the college students' language proficiency in each of the macro skills after using Task - Based Dictations; and

3. Propose the potential of periodicals as materials for task - based dictation

\section{Literature Review}

Historically, L. G. Kelly (1969) narrates in his book that dictation was used in the early Middle Ages by teachers who wanted to transmit information to their students in their own 
language because of the scarcity of books. Thus, the following observations were made: (1) students' mistakes in spelling or punctuation were considered unimportant; (2) students' comprehension on the content of the materials was the focus; (3) students' ability to understand and interpret what they had written down was the goal.

Later, in the Audio Lingual era of foreign language teaching, dictation fell into disfavour, as it did to other techniques related to the Grammar/Translation and Direct methods. Now that a more integrative approach to foreign language teaching and learning is favoured by most methodologists, dictation is regaining its former popularity (Stansfield, 1985).Eventually, in the late 1960's, Furman (1968) used dictation to teach and appreciate literature. She discovered that dictation sharpens her students' ears; it sparks questions on literary style, spelling and punctuation. She explains further that as the teacher dictated a line from a story or a poem, all comments must be reserved until the dictation has been completed. While the teacher is reading, he/she should keep interruptions to a minimum by recognizing no student unless the student raises his/her hand to indicate that he/she wishes to have a phrase repeated. Unless punctuation cannot be indicated by the voice she should not inform the writers about the punctuation marks. Nothing will sharpen their listening so much as comparing their written version with the author's. When students ask why, the teacher can only encourage them to answer their questions by pondering on the printed text. Meanwhile, punctuation on the printed page can be assumed to be author's choice. The dictation should be checked in strict conformity with it (except Shakespeare's). As for the variants in spelling, an up to date dictionary will settle disputes.

Later on, some scholars intertwined dictation with the two other skills in learning English, reading and speaking. This was the beginning of incorporating dictation in developing the macro skills of learners. The "Fusion of the Four Skills" by Elkins, Kalikoda and Morain(1972) calls for the interplay of sound and symbol. It is not limited to listening and speaking on one hand, and reading and writing on the other, but rather involves a crossing of speech and written word. Fusion facilitates reinforcement of the four skills. This technique was used at the University of Georgia to provide for the four skills in intermediate language classes. The possibility of fusing all four skills in one exercise, however, has received little attention then.

In 1988, dictation was reappraised and rediscovered into a task-based, student centred teaching technique. After a quarter of a century, as language teachers, Paul Davis and Mario Rinvolucri wrote a book, Dictation: New Methods; New Possibilities (1988), which offers a variety of dictation techniques where students might as well take down part of words, single words, chunks of sentence(s) they decide to change as they are writing them down. Its synopsis shows a wealth of new techniques to extend the traditional language-learning activity of dictation. The activities range from traditional focuses on spelling and punctuation problems to exercises that emphasize personal attitudes and opinions of both teachers and students. The authors make dictation a root of activities suitable for a wide-range of levels and ages; sample texts for many activities, with permission to copy; opportunities for students 
to create their own texts; and a variety of suggested correction techniques and suggestions for using dictation in teacher training.

This move was followed by Riley (1989) who created a technique in dictation that was based on imitation to improvisation. According to her, dicto-comp (dictation composition) may raise learners' awareness of discourse structure, promote practicing the language in a meaningful context, improve listening and writing skills and teach aspects of vocabulary and/or grammar. In dicto-comp, the learners listen as the teacher reads a text to them. The teacher may repeat it several times. Then, the learners write what they can remember without any further help. Here, the learners have to remember the ideas in the text that is more than a hundred words long and express them in the words of the original or in their own words. Dicto-comp, which name comes from dictation and composition, is an experience technique. That is, it reduces the cognitive load of task (in this case a writing task) by preparing the learners well before they do the task. Now, the preparation provides the learners with ideas, language items and text organization so that they can focus in the skills aspect which is writing in the case of dicto-comp.

Then, a view on task-based dictation emerged when Ruth Wajnryb (1990) introduced dictogloss as relatively recent procedure in language teaching. It borrows a little from the traditional dictation (hence part of its name), but in fact is quite distinct from dictation in both procedure and objectives. The analogy begins and ends with the fact that, in both, a passage is dictated. In dictogloss, the style of dictating is focused on a text approach to grammar, the task that follows and the objective of the lesson are all totally different. Here, the learners are obliged to create their own parallel texts. These are semantic approximation to the original text, created out of the learners' own grammatical and linguistic resources.

Unquestionably, dictation (through its variation) incorporates uncountable skills and competencies. Actually, in 2008, Dr. Rahimi, a professor in Shiraz University, Iran, used dictation to improve the language proficiency of his EFL (English as a Foreign Language) students. He investigated the effect of practice with dictation on the learners' proficiency. The experimental group took a dictation in every session of their class for a period of one semester. Each session, the researcher practiced and corrected dictation with them and elaborated on grammatical, phonological, and lexical points in the dictated passage. The results of the study showed that the experimental group made some improvement on the proficiency test and its components except for the vocabulary subtest.

Recently, Snoder and Reynolds (2019) discovered the great potential of dictogloss to improve learners' knowledge of collocation in their study with ELT practitioners. Also, they call for more L2 classroom-based research that further expands the possibilities for dictogloss to increase learners' competence. This may involve examining how the analysis and correction stage of the original dictogloss procedure may be fruitfully used in terms of class sizes and proficiency levels. 


\section{Methodology and Procedures}

The study was guided by the descriptive-quantitative research design. Through descriptive statistics, the interpretations and conclusions from the findings depend on the average scores of the tests conducted in the classroom, while the students' outputs, the teachers' observations during the conduct of the tests, and the informal interview and survey with college teachers validated the test results. The scores were tallied one by one upon descriptive statistics using ordinal scale. This scale was used in measurement when numbers reflected the rank order of the individuals arranged from the highest to the lowest or vice versa.

Moreover, adopted and modified rubrics were used according to the research context to measure and describe the performance of the participants in each skill: listening, reading, writing, and speaking. It was scored from lowest to highest order such as 1 - Novice; 2 Developing; 3 - Competent; and 4 - Exceptional. Each result of the tests for each skill was graded using these rubrics, while the total scores for each skill and each test were patterned according to the descriptive equivalent shown in Table 1.

Table 1: Description of Scores per Skill

\begin{tabular}{ccc}
\hline Weight & Descriptive Equivalent & Statistical Level \\
1 & Novice & $0.00-1.49$ \\
2 & Developing & $1.50-2.49$ \\
3 & Competent & $2.50-3.49$ \\
4 & Exemplary & $3.50-4.00$ \\
\hline
\end{tabular}

Source: Author

Initially, an informal survey was conducted to twelve (12) experienced English Language teachers from a Catholic university in Manila to assess the use of dictation in the classroom of college students. It was found out that ten (10) out of twelve (12) said teachers, are targeting the macro skills of their students in every lesson they discuss in class. Furthermore, nine (9) of them agreed that dictation can improve the language proficiency of college students. However, half of the group, (6) teachers, admitted that they do not practice dictation in their class. This prompted the need to continue the study on proving the effectivity of Task-based Dictation in improving the college students' English language proficiency.

Thus, materials for dictation were prepared as suggested by Prodomous (1983) which "dialogues and short talks, news broadcasts, and other spoken varieties can be substituted for the traditional bits of prose. A context can be provided by visual aids or an introductory discussion, to add reality to the exercise and to prevent boredom that often fills the vacuum in which traditional dictation is presented." Hence, a set of criteria on the choice of news selections for dictation was formulated. The choices satisfied the following criteria:

A. General appeal. Only prose articles/stories of general and universal appeal were used. Guided byWajnryb (1990), the text produced should make logical sense in terms of the human's knowledge in the real world. Thus, topics such as love, ambition, 
success, human pathos, etc. were particularly chosen because they are interesting to young people.

B. Morale booster. Articles that give inspiration are included since they influence selfesteem.

C. Clarity of language and style of exposition. The text should be grammatically accurate, abiding by syntactic and structural rules of English usage. Second, it should be textually cohesive (Wajnryb, 1990). Hence, articles chosen are easy to understand - simple vocabulary and familiar context.

D. Interdisciplinary weaving. The materials do not limit itself to one subject matter but to several interrelated disciplines. There is the sense of the text as culture-specific in this case to English. Language, is of course, culture specific, and in the textual organization of each, these models lies a cultural basis which the understanding has great value for the language learner. Continued and regular exposure to and construction of these characteristic text types will facilitate the language learners' understanding, appreciation, and manipulation of the logical and rhetorical world of English (Wajnryb, 1990)

For the data gathering, the three-part dictation: Pre-test, Task-based and Post test was used. Recorded audio materials for the pre-test and post-test were selected based on the criteria set in the development of materials. The instructions were included in the recorded audio material for consistency and clarity of the procedure. There was a total of 110 college student participating from three different English classes in a Catholic university in Manila. Specifically, they were enrolled in the courses of Business Administration, Hotel Management, Mass Communication, Education, Information Technology, Psychology, Engineering, and Architecture.

\section{Pre-Test Dictation}

The college students listened to the selected recorded audio material. Altogether, the news item was read four times. During the first reading, which was read at normal speed, they only listened and tried to understand the meaning. For the second and third readings, the passage was read sentence by sentence, or phrase by phrase, with intervals of 15 seconds. The last reading was done at normal speed again and during this time they were asked to check their respective work. They were then given 2 minutes to check through their work once more.

\section{Task-Based Dictation (TBD)}

Each class with 30-35 students was divided into four groups with seven to eight members in a group. Each group has volunteer lead student who was tasked to read and dictate the news item to the group. The content of the news items for dictation of each group were different from one another, but the length and difficulty were equivalent.

Guided by the four stages of Dictogloss presented by Wajnryb (1990) with the teachers' facilitation, each group underwent the following stages: 
- Preparation: The teacher prepared the college students for the text they would be hearing through topical warm-up on the subject matter which made them more receptive to the listening in the next stage. This stage prepared them also for the vocabulary of the text. Since the texts chosen were at the advanced level which ranged from lower advanced to very advanced learners, vocabulary was pre-taught to prevent difficulty during listening. This was also the part where the teacher oriented the lead students and their members about the instructions of each procedure.

- Dictation: Lead students instructed their respective members that they would hear the dictation twice. For the first time, they would listen without writing. The second time, they would start writing notes. Students were encouraged to write down words that would help them piece together the text in preparation for the reconstruction stage. The text was dictated at normal spoken speed following the pace of news broadcasting. The pauses between sentences were slightly longer than usual.

- Reconstruction: When the dictation was done, the members of each group reconstructed their notes by pair and compose their own version of the text without time limit.

- Analysis and Correction: When their text was complete, each pair checked the respective composition of another pair based on the writing rubric (organization, coherence and written presentation).After the lead student explained the writing rubric; the teacher posted each selected news items on the board. Then, in each group, the pairs read, analyzed and corrected another pair's version of the news item. They are encouraged to write corrections on the pair's work. Finally, the papers were returned to each pair. Each pair reads to the class their version of the news item with the correction done by another pair. During the correction process, students were encouraged to ask questions to the lead student and the teacher who acted as the facilitator since the class was open for the discussion of the corrections.

\section{Post-Test Dictation}

Another audio material was played to the class following the instructions in the pre-test (from the same source) dictating a different news item.

\section{Results and Discussion}

At the onset, the mean scores on the pre-test were significantly low. As the results indicate 1.47 in listening, novice; 1.42 in writing, novice; 1.96 in reading, novice; and 2.16 in speaking, developing. This means the students' performance in a traditional dictation procedure is novice, 1.75 . This proves that they have little ability to identify key information through listening which resulted to undeveloped written ideas with little ability to apply sound/symbol relationships to decode the words in reading. Moreover, based on the outputs, they did not use appropriate grammar in basic sentences.

Then, the mean scores in Task Based Dictation (TBD) has significantly improved to 2.93 in listening, competent; 2.49 in writing, developing; 2.93 in reading, competent; and 3.16 in 
speaking, competent. Their skill improvement summed up to 2.88, this time as being competent. This positively shows students' accurate identification on key information through listening, which resulted to adequately organized and clearer yet still incomplete writing, based on the outputs. Surely, they have comprehended level appropriate texts in reading and used appropriate grammar in basic sentences with a clear voice in speaking.

Finally, the mean scores in the post test show a remarkable difference and some improvement. Though the mean score in listening decreased to 2.89 , it is still under the category of competence. As expected, the mean score in writing improve to 2.89 (competent) which means the students showed a well-organized, complete, concise and clear thought with sufficient details in writing. Likewise, the reading mean score of 3.68 (exemplary) shows accuracy in comprehending level appropriate texts in applying sound symbol relationships to decode vocabulary. Lastly, the mean score in speaking increased to 3.27 (exemplary) which implies that the students almost always used appropriate grammar in basic sentences and almost always used appropriate vocabulary with comprehensible pronunciation in speaking.

The results show (refer to Table 2) that there is a significant difference between the means on the pre-test, TBD and post test. Since the mean scores of the students in all the cases have increased from the TBD to the post test, it can be said that the TBD has a positive effect on the improvement of the proficiency of the students when compared with the results of the pre-test wherein the students were not oriented yet with TBD. Indeed, the process of TBD helped in improving the proficiency of the college students in Reading, Writing and Speaking. As shown in Table 4, there is no difference between the scores of the students in the Listening skills in the pre-test compared to the post test scores of the college students. Since the mean for the post test in writing, reading, and speaking are higher than in the pretest, it can be said that the use of TBD has contributed to the improvement of the college students' proficiency in the English language.

Table 2: Mean Scores of the Students in the Pre-test, TBD and Post-Test

\begin{tabular}{ccccccc}
\hline \multirow{2}{*}{ Skills } & \multicolumn{2}{c}{ Pre-test } & \multicolumn{2}{c}{ Tests } & \multicolumn{2}{c}{ Posk Based Dictation } \\
& Score & Equivalent & Score & Equivalent & Score & Equivalent \\
Listening & 1.47 & Novice & 2.93 & Competent & 2.89 & Competent \\
Writing & 1.42 & Novice & 2.49 & Developing & 2.89 & Competent \\
Reading & 1.96 & Novice & 2.93 & Competent & 3.69 & Exemplary \\
Speaking & 2.16 & Developing & 3.16 & Competent & 3.27 & Competent \\
Total & $\mathbf{1 . 7 5}$ & Novice & $\mathbf{2 . 8 8}$ & Competent & $\mathbf{3 . 1 8}$ & Competent \\
\hline
\end{tabular}

Source: Author

Meanwhile, the teachers' observations (in Table 3), during the facilitation of the stages of the dictation, were collected through informal interview. This informal data analysis validated and contrasted some of the results in the task-based dictation stage. 
Table 3: Informal Data Analysis of the Teachers' Observations during the Facilitation of the Task-Based Dictation (TBD)

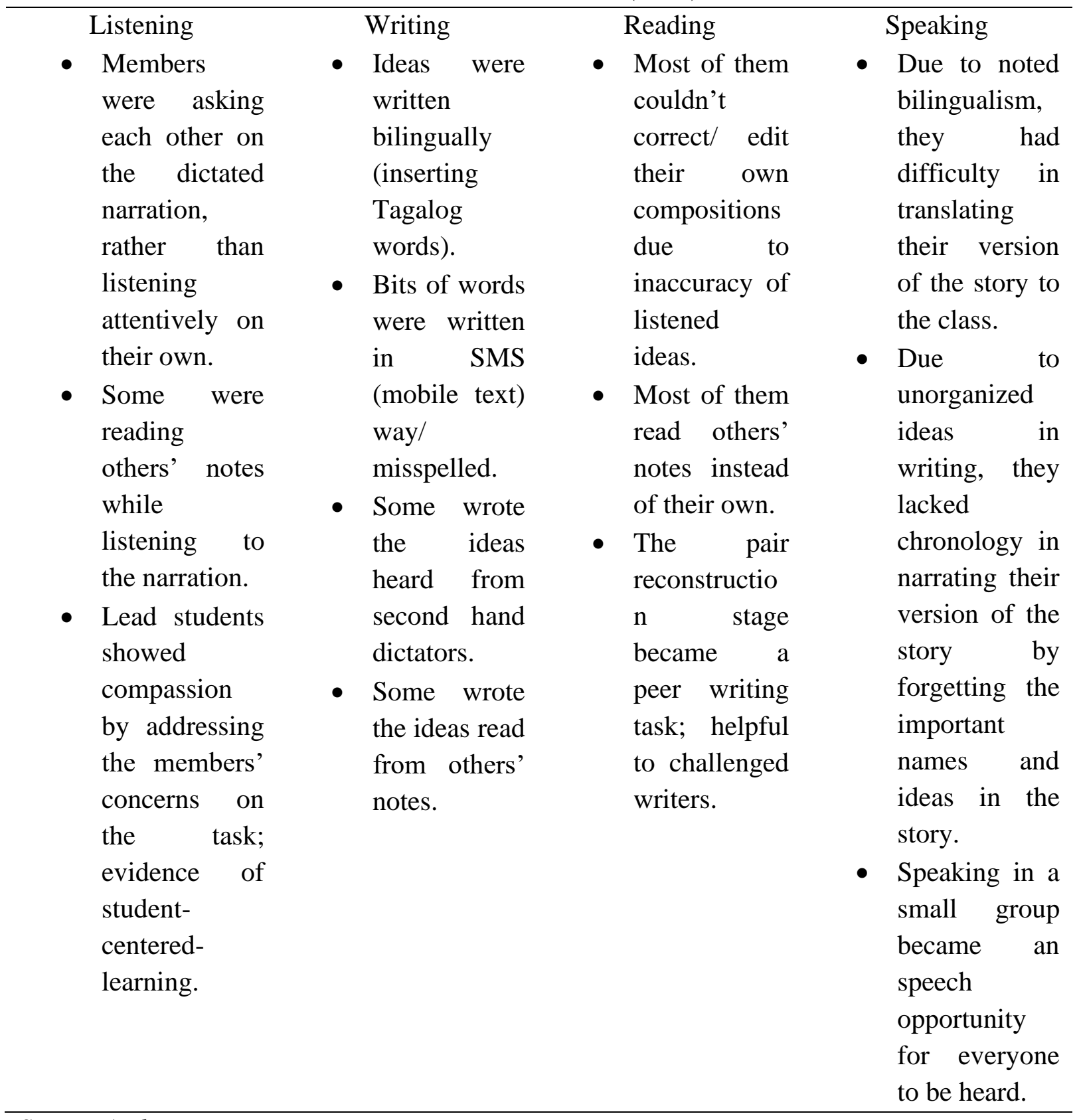

Source: Author

\section{Conclusion and Suggestion}

Despite its limitations, this study answered the reservations of dictation in improving the English language proficiency of college students by increasing their competencies of their macro-skills (reading, writing, listening and speaking). First, class dictations using authentic materials, such as periodicals, are beneficial to students at tertiary level, as they help perfect listening and writing skills, raise awareness on problematic language areas, and avoid biases in analyzing texts. Second, class discussions are designed to create a friendly learning environment in which students collaborate in pairs or small groups. Third, TBD provides 
opportunities for each learner to compare his/her written work with a peer's work. Fourth, post dictation comprehension exercises proved beneficial, but pre-teaching vocabulary might be optional depending on the students' general proficiency in language. Finally, self-checking of one's written work by comparing it with the original transcripts of the dictated material allows students to assess their achievements individually.

Based on the results of the data gathered and observations done in the course of applying $\mathrm{TBD}$, the following are recommended:

- Listening activities contribute to the language development of the students especially when associated with writing, reading, and speaking. Therefore, it must always be part of the syllabi or curriculum not in English subjects but in other disciplines.

- Periodicals are potential tool to improve language proficiency. They are not only reading materials but also listening, writing, and speaking materials for multidiscipline lessons. The availability of authentic materials online makes it more convenient for teachers and students to collate and classify them according to their language needs.

- TBD promotes peer feedback which imposes students' roles especially in writing tasks. Undeniably, teaching writing could be challenging to some teachers. Thus, TBD may give positive attitude to students towards writing and offers a student-centred assessment to teachers of writing.

- Teachers can explore and revive dictation and periodicals for skill building exercises in multi-discipline subjects unrestricted to language teachers.

\section{Acknowledgements}

The author is grateful to her loving husband, Robert Bon, and her son, Mateo. She thanks her parents, Antonio (+) and Victoria, and siblings, Vianne and Anthony, for their love and support. She expresses her gratitude to all her mentors at Philippine Normal University, particularly Dr. Ma. Antoinette C. Montealegre, for guiding her in writing this research paper. Lastly, she is indebted to the contribution of her beloved students and colleagues for making this study possible.

\section{Conflict of Interest}

The author declares no conflict of interest during the preparation and submission of this paper.

\section{Funding}

The author solely funded and financed this study as the final paper requirement in her master's degree program in Teaching English Language Arts. 


\section{References}

Alkire, S. (2002). Dictation as a language learning device. The Internet TESL Journal, 8(3), 1.

Alinsunod, J. (2014). A study on common writing errors of engineering students: A basis for curriculum development. European Journal of English Language and Literature Studies, 2(3), 7-15.

Betz, A. (1918). The Function of dictation in the teaching of modern languages. The Modern Language Journal, 2(4), 150-156.

Bott, D. E. (1986). Easy and Accurate Assessment of "co-co". English Teaching Forum, 24 (3), 42-43.

Brown, D. (1972). Principles of language learning. New York, USA: Pearson Education.

Brown, G. (1987). Twenty-five years of teaching listening comprehension. In English Teaching Forum, Vol. 25, No. 4, pp. 11-15.

Brown, D. (2004). Language assessment principle and classroom practices. New York, USA: Pearson Education

Casambre, N. J. (1982). The Impact of American Education in the Philippines. Educational Perspectives, 21(4), 7-14.

Creswell, J. W. (2005). Educational research: planning, conducting, and evaluating quantitative and qualitative research $\left(2^{\text {nd }}\right.$ ed $)$. New Jersey, USA: Pearson Publication

Davis, P. \&Rinvolucri, M. (1988 ). Dictation: New methods; New possibilities. United Kingdom: Cambridge University Press.

Davis, P., \& Rinvolucri, M. (1988). Dictation.: New methods, new possibilities. Ernst Klett Sprachen. (1990, January). Dictation: An Old Exercise - a New Methodology. English Teaching Forum, 28 (1), 49-50.

Elkins, R. J., Kalivoda, T. B., \& Morain, G. (1972). Fusion of the four skills: a technique for facilitating communicative exchange. The Modern Language Journal, 56(7), 426-429.

Ellis, R. (1986). Understanding second language acquisition. New York, USA: Oxford University Press.

Ellis, R. (1997). Tasks in SLA and language pedagogy. Task-based language learning and teaching. New York, USA: Oxford University Press

Espinosa, D. (1997). English in the Philippines. Global Issues in Language Education, 26(9).

Furman, A. (1968). "Dictation: 1968”. The English Journal, 57, 1166-1186.

Hunt, S., Sparkman, R. Jr., \& Wilcox, J. (1982). “The Pretest in Survey Research: Issues and Preliminary Findings". The English Journal, 57, 1166-1186.

Jacobs, G., \& Small, J. (2003). Combining dictogloss and cooperative learning to promote language learning. The Reading Matrix, 3(1).

Keh, C. L. (1989,January). The use of dicto-comp in form six. English Teaching Forum, 27 (1).

Kelly, L. G. (1969). 25 Centuries of Language Teaching. USA: Newbury House Publishers Kilickaya, F. (2004). "Authentic Materials and Cultural Content in EFL Classrooms". The Internet TESL Journal, 10 (7). 
Lawrence, P.M., \&Levinsonk B.F. (1987). Dictation Alive and Well. The English Journal, 10 (7).

Manzi, K. (1972). Why is dictation so frightening. English Teaching Forum, 30 (2).

Masangya, E. M., \& Lozada, L. (2009). An Investigation on the relationship between the language exposures and errors in English essays of high school students. Philippine ESL Journal, 2, 31-50.

Morris, S. (1983). Dictation — a technique in need of reappraisal. ELT Journal, 37(2), 121126.

Nation, P. (1991). Dictation, dictocomp and related techniques. EnglishTeaching Forum, 9 (4), 12-14.

Norris, R. W. (1993). Using creative dictation to manage, motivate, and activate large groups of false beginners. Fukuoka Women's Junior College Studies, 45, 71-82.

Nunan, D. (2004). Task-based language teaching. Mississippi, USA: Cambridge University Press.

Pedromou, L. (1980). Dictation: pros, cons and procedures. English Teaching Forum 21 (1), 37-38.

Rafael, V. L. (2015). The war of translation: Colonial education, American English, and Tagalog slang in the Philippines. The Journal of Asian Studies, 283-302.

Rahimi, M. (2008). Using dictation to improve language proficiency. Asian EFL Journal, 10(1), 33-47.

Raman, M. (2014). "Promoting Integrated Language Learning through Dictogloss". International Journal of English and Literature (IJEL), Special Edition, 53-58.

Riley, P. (1972). The dicto-comp. English Teaching Forum 10 (1).

Rivera, C. (1984). Language Proficiency and Academic Achievement. Multilingual Matters 10. Multilingual Matters Ltd.

Snoder, P., \& Reynolds, B. L. (2019). How dictogloss can facilitate collocation learning in ELT. ELT Journal, 73(1), 41-50.

Skehan, P. (2003). Task-based instruction. Language Teaching 36. 1-14.

Speer, T. M. (1980, July). Putting variety into dictation. English Teaching Forum 18 (3).

Stansfield, C. W. (1985). A history of dictation in foreign language teaching and testing. The Modern Language Journal, 69(2), 121-128.

Sutherland, K. (1967,March). Dictation in the language classroom. English Teaching Forum $5(2)$.

Valderama, T. C. (2019, November 18). Pinoy's English proficiency declines sharply. The Manila Times.Retrieved from https://www.manilatimes.net /2019/11/18 /opinion/ columnists /topanalysis/pinoys-english-proficiency-declinessharply/656784/\#: : text= Filipinos\%20have\%20been\%20known\%20to,speaking\%20countries\%20in\%20the\%20 world.

Wong, A., \& Leeming, P. (2014). Using dictation to measure language proficiency. Language Education in Asia, 5(1), 160-169. 